\title{
Un proyecto de arquitectura del hierro desde Andalucía: el mercado para Cáceres de Adulfo del Castillo, 1884
}

\author{
José Manuel González González \\ Universidad de Granada \\ profeman@ugr.es
}

RESUMEN: Presentamos un ejemplo inédito de la arquitectura del siglo XIX, el proyecto de mercado para Cáceres de Adulfo del Castillo (1884), una muestra atractiva por su volumen y presupuesto. Interesan sus alzados y plantas, avanzados por ser un modelo mixto de arquitectura del hierro y de otros materiales, pero también que se contrate desde Extremadura a un arquitecto andaluz para realizar el proyecto, cuando había dos arquitectos titulados en Cáceres. Se analiza primero el desarrollo de los mercados metálicos en España, haciendo especial hincapié en Extremadura, y después el impacto urbanístico que esta medida suponía para la ciudad, pues incluía demoliciones para regularizar una de las plazas más tradicionales de la localidad, la Corredera de San Juan. El mercado no se realizó, pero sí las demoliciones.

PALABRAS CLAVE: Arquitectura del hierro, Siglo XIX, Mercado, Andalucía, Cáceres, Adulfo del Castillo, Arquitectura española.

\section{A Project of Cast-Iron Architecture from Andalusia (Spain): Market for Cáceres by Adulfo del Castillo, 1884}

ABSTRACT: We present an unknown example of the architecture of the nineteenth century - the market design drafting for Cáceres (1884) by Adulfo del Castillo, an attractive sample for its size and budget. Of interest are not only the advanced elevation and floor, which are a mixed model of cast-iron architecture and other materials, but also the fact that an Andalusian architect was called to Extremadura to carry out the project when there were two qualified architects in Cáceres at that time.

Firstly, the development of the metal markets in Spain is analyzed, with a particular emphasis on Extremadura. Then also analyzed is the urban impact that this measure meant for the city, since it included some demolitions to regulate one of the most traditional places of the town - the Square of San Juan. The market place was not constructed, but the demolitions went ahead.

KEY WORDS: Cast-Iron Architecture, XIX th Century, Market, Andalusía, Cáceres, Adulfo del Castillo, Spanish Architecture.

Recibido: 3 de febrero de 2015 / Aceptado: 16 de junio de 2015.

\section{Introducción. Mercados de hierro en la España finisecular}

Con este artículo pretendemos dar a conocer este proyecto de mercado, el más antiguo de los que se acometen en Extremadura, y que sitúa a esta pequeña ciudad a la vanguardia de este tipo de arquitectura del hierro, pues hubiera sido uno de los primeros mercados cubiertos construido fuera de las provincias de Madrid y Barcelona.

Como sabemos, la construcción de nuevas tipologías arquitectónicas alcanzó en el siglo XIX cotas hasta entonces desconocidas. Nuevos equipamientos públicos precisaban de un modelo adecuado para su cobijo, y con la influencia de los historicismos surgieron edificios que pueden considerarse representativos de esta nueva época. El progreso de la ingeniería ayudó enormemente y la aplicación y mejora de materiales poco usados como el hierro o el cristal hicieron el resto. La búsqueda de modernidad y el abaratamiento de algunos procesos dieron el empuje definitivo.

GONZÁLEZ GONZÁLEZ, José Manuel: «Un proyecto de arquitectura del hierro desde Andalucía: el mercado para Cáceres de Adulfo del Castillo, 1884», Boletín de Arte, n. ${ }^{36}$, Departamento de Historia del Arte, Universidad de Málaga, 2015, pp. 93-101, ISSN: 0211-8483. 


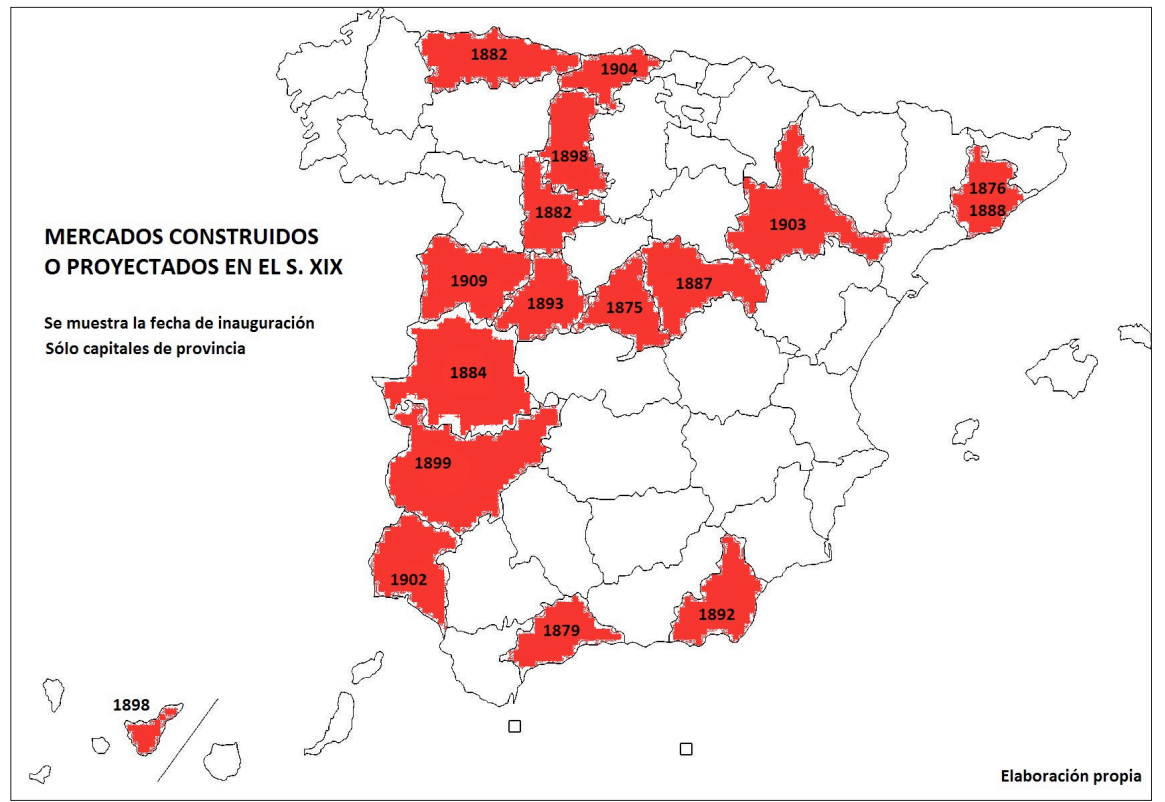

1. Mercados construidos 0 proyectados en las capitales de provincia a finales del siglo XIX
De entrada, la idea de cubrir y proteger los espacios tradicionalmente dispuestos para el comercio en las plazas, pretendía subsanar cuestiones higiénicas y mejorar el control de esta actividad económica. Como corolario, numerosos edificios de mercados de abastos surgen por toda Europa, España y también Extremadura, evidenciándose en nuestro país una clara influencia de Francia, especialmente en el último cuarto de siglo XIX, que es cuando el modelo se instaura.

En España en este periodo se inauguran dos en Madrid (Cebada y Mostenses, 1875, de Calvo Pereira) y se erigen varios en Barcelona; entre 1876 y 1888 Borne, San Antonio, Barceloneta, Hostafrancs y Concepción, todos de Rovira y Trías salvo el primero que era de Fontseré y de Cornet y Mas'.

A estos primeros ejemplos habría que añadir otras capitales de provincia que construyen a finales del XIX [1]; es el caso de Málaga (1879, del arquitecto Joaquín Rucoba), Valladolid (1878-1882, de Ruiz Sierra, reformado en 1904 y llamado del Val2), Oviedo (1882, de Javier Aguirre), Guadalajara (1880-1887, de Mariano Medarde), Badajoz (18901899, de Tomás Brioso), Almería (1892, de Trinidad Cuartara), Ávila (1893, de Repullés y Vargas, desparecido), Tenerife (1894-1898, de Antonio Pintor), Zaragoza (1895-1903, de Félix Navarro), Palencia (1895-1898, de Juan Agapito y Revilla ${ }^{3}$ ), Santander (1897-1904, de Eduardo Reynalds y Juan
Moya), Salamanca (1898-1909, de Joaquín Vargas) o Huelva (1899-1902, de Pérez González). Sin ser capitales también conviene citar los de Jerez de la Frontera (1873-1885, de Esteve Guerrero) y Gijón (1898, de Mariano Medarde).

Como podemos apreciar por el crecido número de ejemplos en las capitales de provincia, el modelo tuvo éxito y se distribuyó por toda la geografía, aunque especialmente por el norte y el oeste.

En la región extremeña como muestras más destacadas tenemos Mérida (1885-1887), Badajoz (1890, $1897-$ 1899) y Trujillo (1896); los dos primeros se conservan, con algunas modificaciones, y el tercero desapareció hace unas décadas. Otros mercados cubiertos les seguirían en las primeras décadas del siglo XX, pero se alejan por estética del modelo aquí tratado.

El primer mercado citado y el más antiguo de los extremeños es el de Mérida, conocido como Mercado de Calatrava. Es una recoleta obra, de una sola planta, con calles interiores descubiertas, y construida por el arquitecto provincial Ventura Vaca en abril de 1885, aprovechando un solar desamortizado a la Iglesia4. El proyecto es interesante pues sigue la moda madrileña, conjugando la corriente neomudéjar al exterior mediante el uso del ladrillo con algunas piezas interiores de arquitectura del hierro. La decoración es sencilla, aunque bien compuesta 5 . Fue ampliado a mediados del siglo 


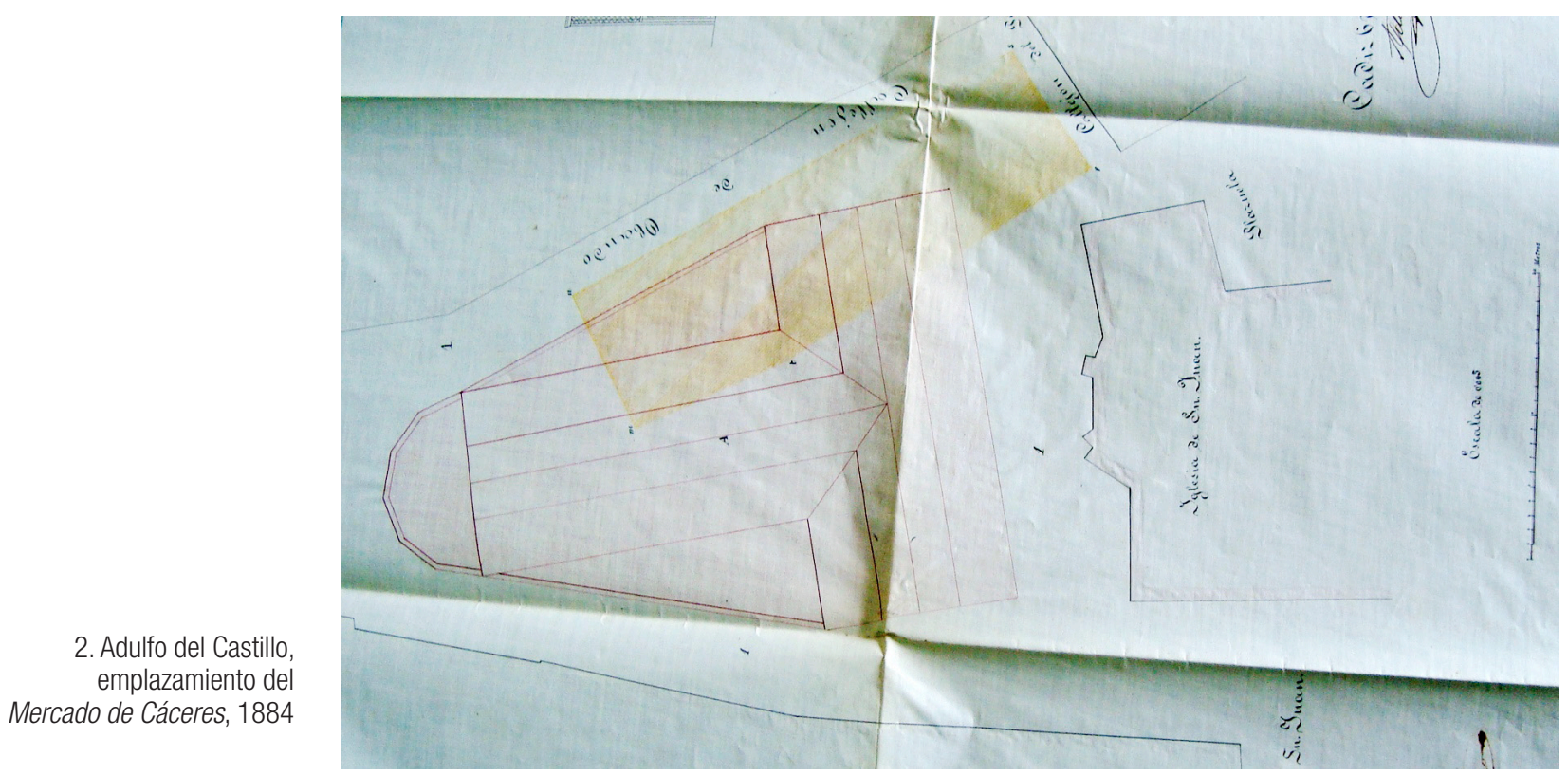

XX con un amplio sótano y cubierto en su integridad; todavía conserva su uso original, especializado en productos frescos.

El de Badajoz es el mejor ejemplo de la arquitectura del hierro en Extremadura, por su tamaño, grandiosidad y buen gusto, y es el único edificio del siglo XIX declarado por el gobierno regional bien de interés cultural. Conocido como el Mercado Metálico, se situaba en la plaza Alta y fue proyectado por Tomás Brioso. Tiene 60 metros de largo por 23 de ancho y 10 de alto y se compone de tres naves, de forma basilical. La estructura metálica, a base de finos pilares de hierro, se cubre con una cubierta de zinc, y apoya sobre una base que combina sillares de piedra y paños de ladrillo. La decoración bebe en las fuentes académicas, siendo evidente la serliana clásica, las acróteras de recuerdo griego o los arcos de medio punto habituales en el Renacimiento. El cuidado de la iluminación era muy adecuado a su uso y dotaba al interior de una atmósfera fabril mediante luces cenitales, celosías, persianas de madera y ventanas acristaladas. El inmueble fue trasladado en la década de 1970 a un nuevo emplazamiento, al campus universitario donde actualmente espera una oportuna rehabilitación. Creemos evidente la influencia del Mercado de las Atarazanas de Málaga proyectado por Joaquín de Rucoba unos años antes ${ }^{6}$.

El de Trujillo (1896-1897, de Eduardo Herbás) ${ }^{7}$ tenía una sola planta y algunos toques orientales en sus capiteles, siendo interesante la disposición de un cuerpo superior a modo de pérgola que ventilaba e iluminaba el cuerpo central del edificio y permitía una mayor elegancia y reclamo del edificio.

\section{El proyecto para Cáceres, Adulfo del Castillo, 1884}

Corría raudo el pensamiento en la ciudad y sus vecinos de que un mercado cubierto era condición necesaria para dar imagen de ciudad culta. A nadie se le ocultaba el beneficio que una obra de tal calibre ocasionaría en el comercio, fomentándolo. Quizás por ello, a principios de 1883, la llegada de una carta de la Empresa General de Construcciones, con sede en Madrid, aceleraba las cosas, siendo bien recibida por el Ayuntamiento.

La empresa ofrecía toda clase de facilidades, prometía mandar un ingeniero para que estudiara el modelo a aplicar y se mostraba dispuesta a aceptar cualquier superficie, siempre y cuando esta se le entregara nivelada y despejada. El tiempo de explotación sería de cincuenta años. El municipio decidía que el arquitecto municipal de entonces, Emilio María Rodríguez, hiciera un plano con la posible ubicación del mismo en la Corredera o plaza de San Juan [2], plano en el que ya se evidenciaba la necesidad de derribar algunos 


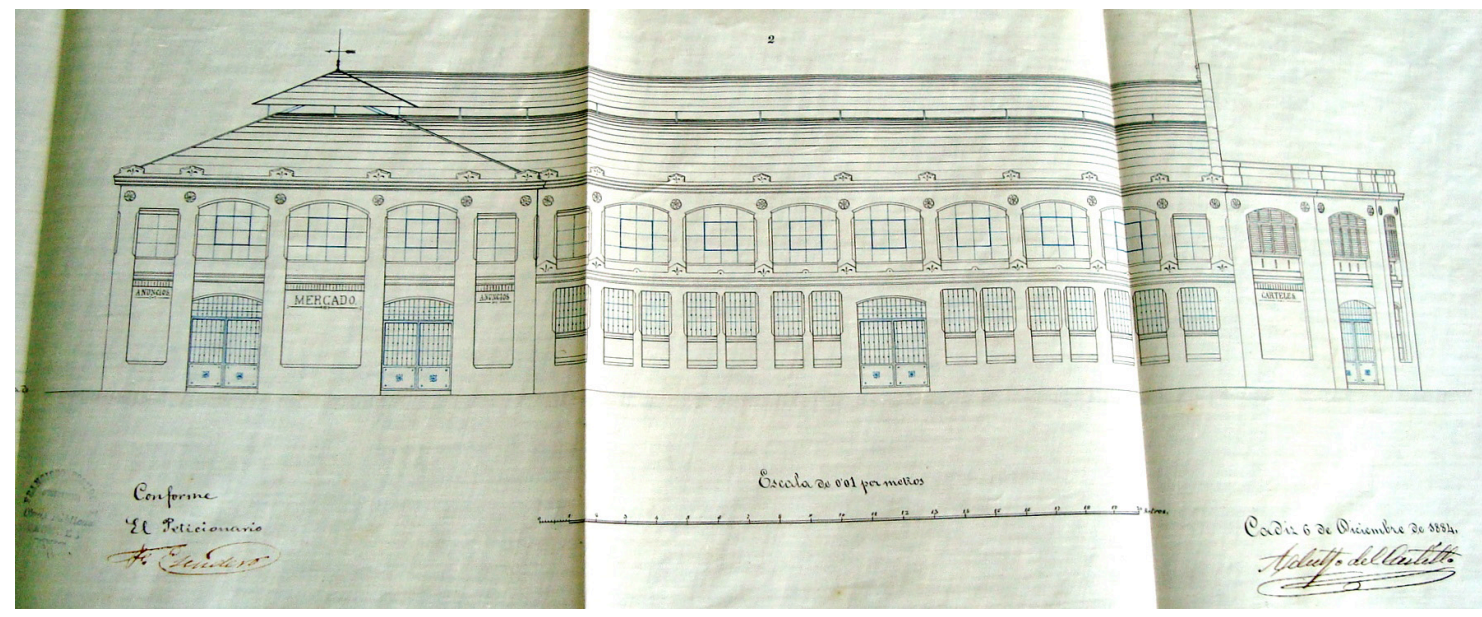

3. Adulfo del Castillo, Proyecto de Mercado de Cáceres, 1884, alzado

inmuebles ${ }^{8}$, demoliciones que se llevarían a cabo antes del nuevo siglo.

Redactado el plano y conocido el hecho en la ciudad, para evitar que fueran forasteros los que realizaran la obra, el contratista local Francisco Escudero, se va a Cádiz y encarga al arquitecto sevillano Adulfo del Castillo un proyecto, que presenta poco después ${ }^{9}$. Desconocemos, eso sí, si se conocían previamente, aunque puede que Escudero visitara el sur con frecuencia.

El proyecto de Cáceres $^{10}$, concebido en diciembre de 1884 por el arquitecto Adulfo del Castillo en la corredera o plaza de San Juan, es el mercado más antiguo proyectado en la región y, aunque nunca se llegó a realizar, conservamos los planos [3] que nos aportan una interesante información estética y vienen a completar parte del trabajo de este autor ecijano. Se trata de una obra admirable, siendo el plan más ambicioso de la localidad en ese siglo, tras la construcción del nuevo Ayuntamiento cacereño en 1869. El empleo del hierro para la cubierta y algunos pilares interiores Ilama la atención [4].

Adulfo del Castillo Escribano (1837-1893) fue un arquitecto titulado en 1863 que trabajó sobre todo en Andalucía, especialmente en Cádiz donde llegó a ser profesor de Bellas Artes y arquitecto provincial, si bien está documentada su actividad en distintos cargos a lo largo de la segunda mitad del s. XIX. Posee obra en el Puerto de Santa María ${ }^{11}$, La Línea de la Concepción ${ }^{12}$ y otras localidades gaditanas.
Este proyecto de mercado es fruto de un encargo particular de un empresario, lo cual habla de un profesional conocido, cualificado y recomendado. De hecho, en la memoria él mismo destaca que no era la primera vez que hacía un edificio con este destino. El documento está firmado en Cádiz y en él afirma que era arquitecto de la Real Academia de San Fernando.

Para poder realizar el edificio, el contratista planteaba derribar una manzana de casas, sin mucho coste. Esta estrecha y alargada manzana de casas ocupaba una superficie de 445 metros cuadrados, por lo que quitaba espacio a la plaza; tampoco afectaba a muchos inmuebles, solo 7 propiedades. Además, era una vieja reivindicación del municipio para ennoblecer la zona y Escudero se ofrece a hacerlo sin subvención alguna por parte de la ciudad.

Las circunstancias que obligan a realizar un mercado cubierto son, según Castillo, la importancia para la salud, la moral y la administración que ofrece un edificio de este tipo:

[...] el mercado actual se constituye todas las mañanas en la plaza del Ayuntamiento con unos setenta ú ochenta vendedores de todas clases en otros tantos puestos al descubierto, en el suelo casi todos, y cuya gran mayoría se quitan a las diez de la mañana, habiendo ocupado por término medio una superficie de ciento cincuenta metros cuadrados, no excediendo el puesto mayor de tres metros, ni el menor de un metro superficiales, f. 5 de la memoria. 


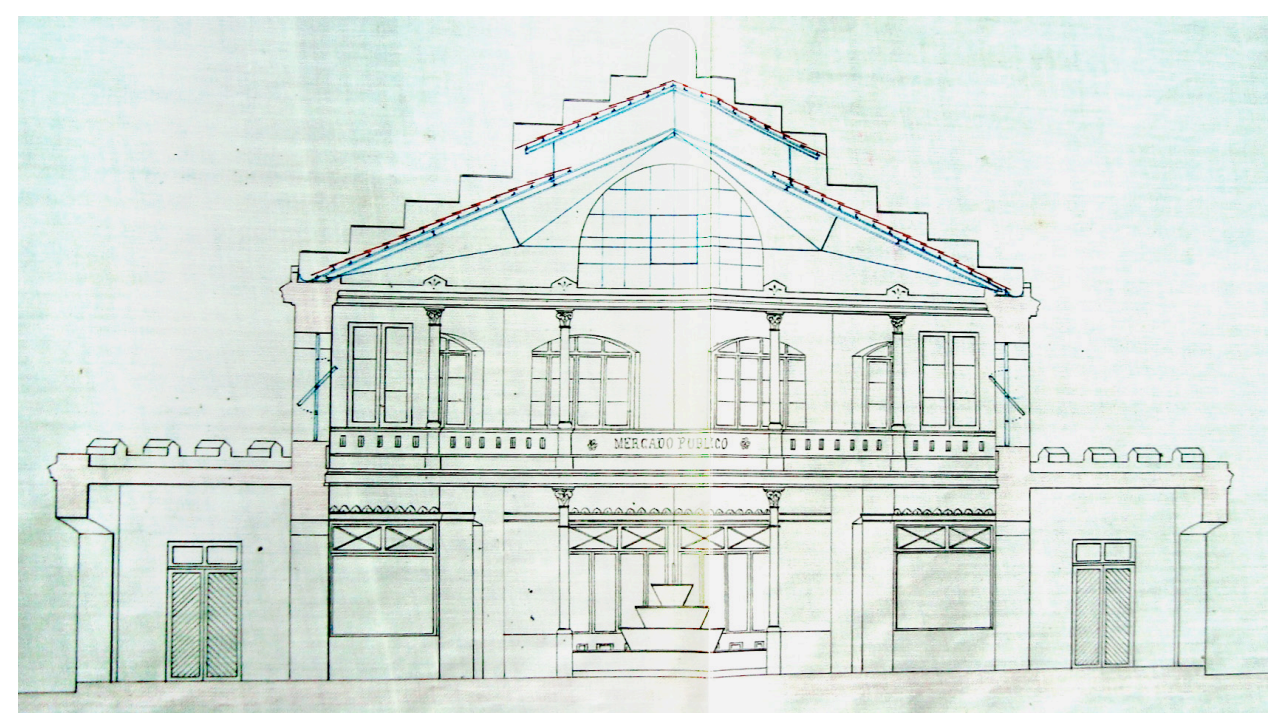

4. Adulfo del Castillo, Proyecto de Mercado de Cáceres, 1884, sección transversal

Con estos datos, el modelo que adopta del Castillo es el edificio con planta en forma de 'T' pero cerrando el perímetro, lo que crea una apariencia cercana a la de la tapa de un piano de cola, modelo poco común aunque racional [5]. Con dos naves principales, de 14 metros de ancho y 7 de alto, y una longitud de 30 y 24 metros respectivamente, el mercado pretendía ocupar 1.032 metros cuadrados, organizando así un número holgado de puestos y servicios municipales. Se cuidaba especialmente la ubicación de la carga y descarga, las circulaciones y la separación de los distintos productos (verduras, carnes y pescados). En este sentido, los puestos de carnes preveían alicatado de azulejos y mostradores de mármol, y los de pescadería de hierro con tableros de mármol, disponiéndose en un extremo, algo separados. Hay dibujada también una sala de limpieza con bombas de agua y otra de retretes, colocándose una sala en alto para reuniones y trato de los vendedores. Se trata de superficies cubiertas amplias, por encima de la media en obras similares.

En cuanto a materiales, aparte de los anteriormente indicados, en el presupuesto también se señalan otros como la piedra de sillar, el ladrillo, la madera de pino, el cemento portland $\left(110\right.$ pesetas $\left./ \mathrm{m}^{3}\right)$ y el uso combinado del hierro fundido (39,5 pesetas/100 kg) y el hierro forjado; el precio de este último en ese momento era de 56 pesetas $/ 100 \mathrm{~kg}$ para vigas, 71,2 para armaduras y 85 el realizado con for- mas más caprichosas. El cristal que se pensaba disponer era de dos tipos, uno simple y otro de doble grueso $(12,5$ y 19,3 pesetas $/ \mathrm{m}^{2}$ respectivamente). Se incluye también un reloj de cuatro esferas, una bomba de dos cuerpos aspirante e impelente y una fuente, todos de metal y con un coste de $1.250,1.146$ y 265,9 pesetas respectivamente.

Destaca en el diseño la abundancia de luz y ventilación [6]: «Las grandes ventanas de dichas naves serán de hierro y cristal esmerilado de doble grueso, y en la parte central de cada una se dispone un ventanillo grande, giratorio", f. $9 \mathrm{v}$ de la memoria.

Aunque no lo exprese, el sistema de cubierta con linternas de iluminación y aireación sobreelevadas realizadas en hierro y cristal está tomado del Mercado de Les Halles de París, del arquitecto Baltard, una referencia muy habitual dado que fue el primer gran modelo europeo cuya influencia se evidencia en otras muchas obras españolas. Por otra parte, es un elemento de vanguardia, pues usa el sistema inventado por Polonceau unas décadas antes, sistema que dio a conocer a mediados de siglo en varias publicaciones ${ }^{13}$, y que luego perfeccionaría el ingeniero Flachat en sus estaciones de ferrocarril.

Como suele ser común, los cimientos son de mampostería, el zócalo de sillería y los pilares y muros de fábrica mixta de ladrillo y mampostería; a esto se suman impostas 


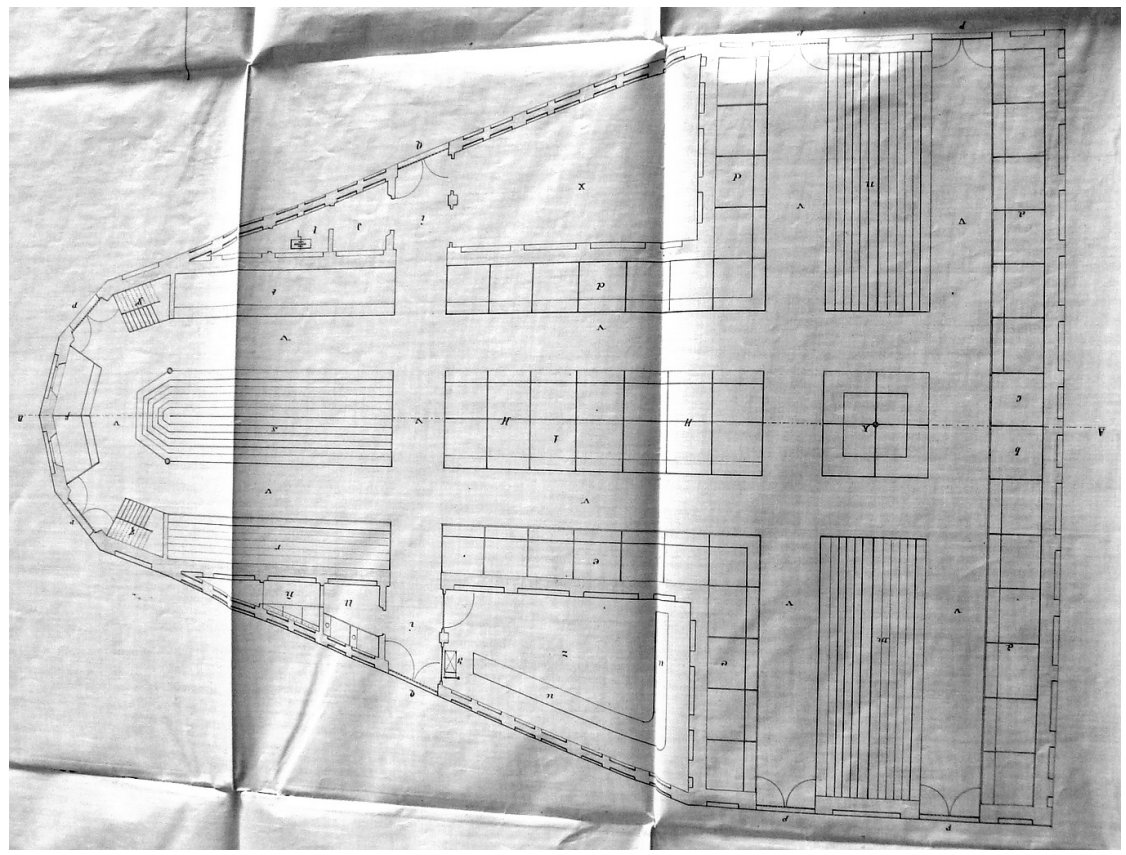

5. Adulfo del Castillo, Proyecto de Mercado de Cáceres, 1884, planta y cornisas de ladrillo, suelo de hormigón (en parte enlosado y en parte adoquinado), techos de viguería de hierro con bovedillas de ladrillo tabicado, columnas de hierro fundido con vigas de hierro laminado, armadura de hierro y cubierta de teja plana de barro.

El arquitecto es pragmático en el uso de materiales, e incluso justifica que en tierras meridionales de la Península no conviene el abuso del hierro o el cristal, pues no se adaptan bien al clima:

Aquí haremos notar que, por los buenos resultados obtenidos en otros mercados que hemos proyectado y dirigido en nuestro país, re[h]usamos el abuso del hierro y los metales en general, cuando no estén envueltos en otros materiales malos conductores del calor, pues harto conocidos son los malos efectos del es[x]ceso de este en la clase de que se trata; y por análoga razón hemos reusado también utilizar grandes luces cenitales, ff. $9 v$ y $10 \mathrm{r}$ de la memoria.

En este sentido, cabe pensar en una cierta influencia de la tesis defendida por Cabello y Asso en el I Congreso Nacional de Arquitectos de 1881, donde casi se repiten las mismas ideas $^{14}$. Por ello proyecta un edificio sólido, si bien bajo el punto de vista artístico cree que «esta clase de construcciones debe ser muy sobriamente decoradas, distinguiéndose por su amplitud y formas bien proporcionadas», f. 10r de la memoria.

El proyecto de Cáceres se adelanta incluso a la opinión del arquitecto Repullés en la vecina capital de Ávila, profesional que también desdeña un cierre metálico por razones térmicas, mostrando una corriente de pensamiento que domina la arquitectura férrea de los mercados en estos momentos ${ }^{15}$.

Estilísticamente el aspecto exterior está cercano al eclecticismo, pues no hay un elemento que pueda asimilarse a un estilo concreto y sí a una cierta influencia centroeuropea y oriental. El uso de falsas pilastras rebajadas en sus perfiles, que enmarcan unos vanos rectangulares, rematados con dinteles o arcos puede estar tomado del mudéjar; el empleo de determinadas rosetas de fábrica, palmetas neoáticas, capiteles clásicos de orden compuesto es influjo del historicismo; la rejería sencilla y los merlones escalonados pueden estar a la moda de la tradición flamenca. Incluso es posible una cierta influencia de modelos barceloneses de esta época y de otras influencias orientales.

El edificio es sencillo exteriormente, pero el uso de vigas de hierro, cubierta a dos niveles y la organización y distribución demuestran un hábil arquitecto, que sabe separar las distintas funciones y puestos necesarios en un mercado 


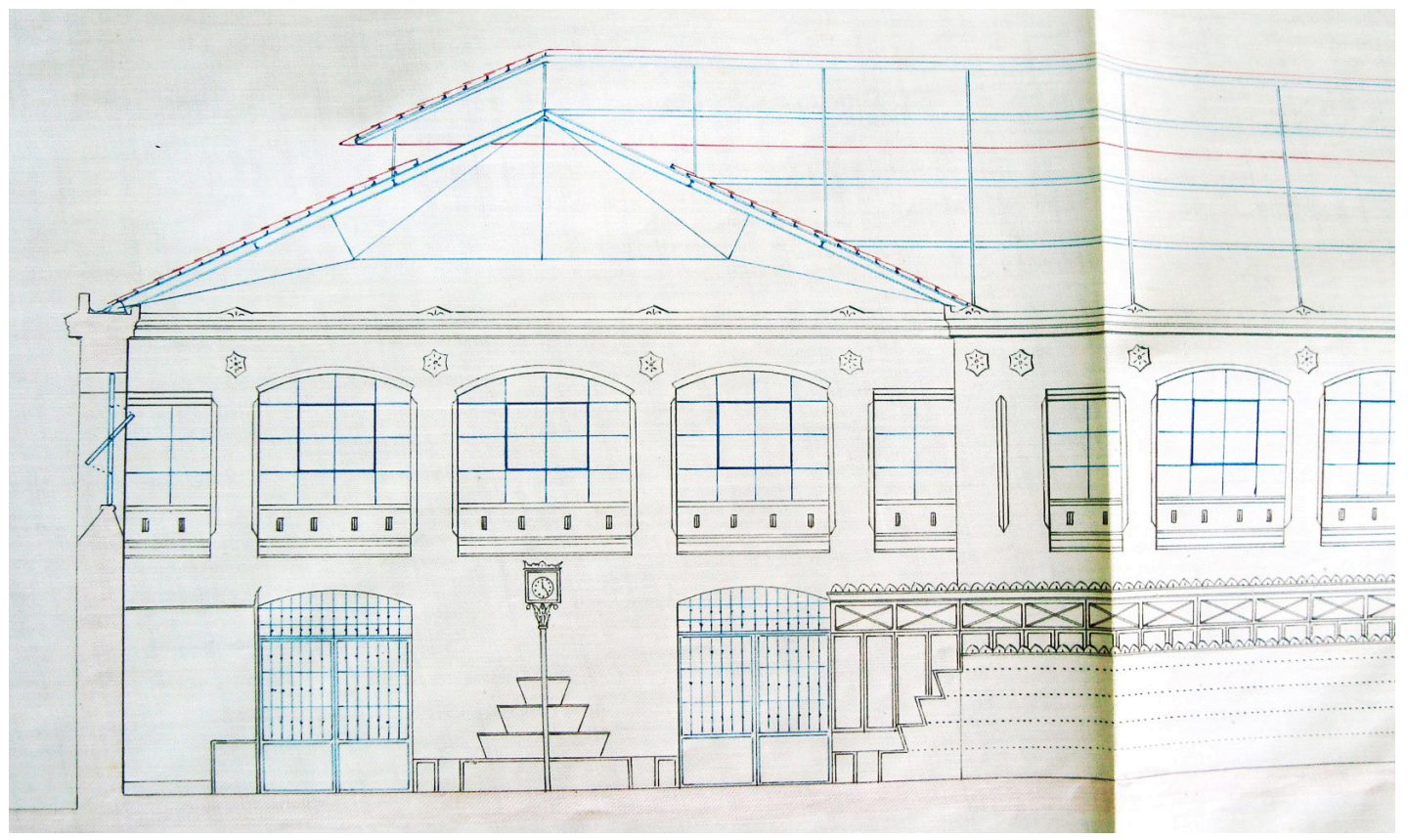

6. Adulfo del Castillo, Proyecto de Mercado de Cáceres, 1884, sección longitudinal

cubierto, y que ordena los macizos y huecos con elegante disposición simétrica, luminosa y de fácil comunicación interior y exterior.

Adulfo del Castillo no tiene reparos en comparar su proyecto con los de Málaga y La Línea de la Concepción, de los que está al corriente; de hecho este último lo conocía muy bien pues, aunque no lo dice, en 1878 lo había proyectado él y se inauguraría cuatro años después ${ }^{16}$. Con un presupuesto de 259.457,41 pesetas, el de Cáceres preveía un coste equilibrado de 252 pesetas el $\mathrm{m}^{2}$, frente a las 283 del primero y las 219 del segundo. Estas comparaciones se traerían para intentar convencer a los regidores municipales de la aprobación del proyecto, claro está, pues es una obra impulsada desde el sector privado.

La iniciativa particular corresponde a Francisco Escudero, contratista de obras públicas y emprendedor local adelantado a su época; Escudero intenta hacer negocio pero también da la posibilidad al Ayuntamiento de solucionar un problema que se enquistaba. Según sus cálculos, al día se ingresarán por concepto de arrendamiento y uso unas 62,5 pesetas. Este tipo de soluciones especiales se emplearon en algunas ocasiones en España, cuando el presupuesto muni- cipal o el estado de endeudamiento del mismo no lo permitía. Conocemos casos españoles similares, pero incluso en Cáceres se había construido la plaza de toros mediante una sociedad local de inversores o accionistas.

A partir de mediados de 1885, un cambio de actitud del Ayuntamiento detiene el proyecto por supuestas carencias legales, considerando que la oferta es onerosa y perjudica a los vecinos ${ }^{17}$, no publicando la misma en las gacetas oficiales, todo ello a pesar de que el gobernador civil insiste en que se realice la subasta de la obra, que había sido declarada de utilidad pública poco antes ${ }^{18}$.

Finalmente en 1886 el Concejo decidió no acometer esta interesante oferta y sí fomentar un proyecto más sencillo $^{19}$, e instalarse donde siempre, ocupando parte del solar libre que había en la plaza mayor junto a la muralla. En consecuencia, se mejora el espacio tradicionalmente usado para carnicería junto a las casas consistoriales ${ }^{20}$, abriendo nuevas casetas o estalaches alrededor. El proyecto es obra del sobrestante Antonio Montoya, y estaba terminado a mediados de ese año ${ }^{21}$.

Tras insistir, un informe legal devolvería al promotor y contratista, Escudero, el depósito que había dejado como 
garantía, abonándosele además, como justa recompensa por el empeño realizado, una cantidad por el proyecto que obraba en el expediente ${ }^{22}$.

Aun a pesar de esta regularización del plano y de la construcción de unos sencillos tenderetes, muchos de los mercaderes permanecerían a la intemperie hasta la construcción de un edificio cubierto en 1931. En un informe municipal de 1910 se afirma que existían 220 puestos y que se iban a mejorar las condiciones de los mismos con un presupuesto de 98.808,01 pesetas según proyecto de A. Montoya $^{23}$. Esta clase de soluciones, circunstanciales, pero prácticas en momentos de crisis y de escasas economías, hablan del poco arrojo o las dificultades económicas y políticas que había que vencer.

\section{Conclusiones}

Con este artículo damos a conocer el fracaso de un proyecto de nuevo mercado y el éxito que el Consistorio cacereño creyó conseguir tras evitar que un particular o una empresa se llevase los beneficios impositivos de este negocio. No obstante, lo que sí perdió fue la estética pública, y a la postre el Ayuntamiento se vería forzado a iniciar un mercado ya en el siglo XX, mercado poco amortizado, ya que acabaría derribándolo en apenas cuarenta años. Cáceres no conserva pues ningún mercado cubierto de interés arquitectónico en la actualidad.

Que el mercado cubierto fue una tipología que duró un siglo, lo muestran la demolición y desaparición de muchos de ellos en décadas pasadas, y la necesidad que ha habido en los últimos años de adaptar los todavía en pie a los nuevos usos y exigencias de la sociedad ${ }^{24}$. La proliferación de tiendas de barrio y la llegada del supermercado dio la puntilla a este tipo de edificios ${ }^{25}$.

Para su pervivencia, triunfa ahora el modelo de mercado exclusivo, de élite, donde no solo comprar productos frescos de alta gama, sino también disfrutar de una experiencia gourmet elaborada con dichas materias primas, una tendencia de rehabilitación que es fruto de lo acaecido en las ciudades más pobladas. En Barcelona desde finales del siglo $X X^{26}$ se ha apostado por la remodelación y adaptación de los mercados: la Concepción, Santa Caterina, Ninot, Barceloneta, Hostafrancs... Y están en proyecto otros como Sant Antoni o La Abaceria Central de Gracia que incorporan una gran superficie y aparcamientos ${ }^{27}$. En Madrid, el ejemplo más conocido y celebrado es el del Mercado de San Miguel que se remodeló a principios del siglo XXI. Estas experiencias se están extendiendo a otras regiones, incluida Málaga $^{28}$, aunque ya hay quien alerta, con razón, que este cambio está afectando incluso a la arquitectura y visión volumétrica de estos edificios, que pierden su autenticidad al mutar sus valores materiales ${ }^{29}$.

En conclusión, hay que exigir la conservación de los pocos ejemplos de arquitectura del hierro que aún queden, pero también evitar que las actualizaciones sean intervencionistas en exceso y desvirtúen estos mercados metálicos que son de los mejores ejemplos de la arquitectura del siglo XIX y que hacen ciudad. 
1 El mejor resumen quizás sea el libro de NAVASCUÉS PALACIO, Pedro, Arquitectura e ingeniería del hierro en España (1814-1936), Madrid, EI Viso, 2007, pp. 226-257. Gran interés tiene también el de CASTAÑER MUÑOZ, Esteve, La arquitectura del hierro en España: los mercados del siglo XIX, Madrid, Real Academia de Ingeniería, 2006

2 CAMINO OLEA, María Soledad, «Los tres mercados de hierro de la ciudad de Valladolid», en HUERTA FERNÁNDEZ (coord.), Actas del Cuarto Congreso Nacional de Historia de la Construcción, Cádiz, vol. I, 2005, pp. 195-202.

3 SERRANO LÓPEZ, Roberto, Arquitectura e ingeniería del hierro en las provincias de Burgos y Palencia (1830-1940), tesis doctoral, Universidad de Burgos, 2011, disponible en: http://riubu.ubu.es/handle/10259/203 (Fecha de consulta: 17-12-2014), pp. 108-115 y 235-254.

4 SÁNCHEZ GAJARDO, Isabel María, «El solar de San Francisco en la arquitectura emeritense del siglo XIX», Norba-Arte n. ${ }^{\circ}$ XXV, 2005 , pp. 149-163.

5 TEIXIDÓ DOMÍNGUEZ, María Jesús, «Los planos del mercado de Calatrava de Mérida», Norba-Arte n. ${ }^{\circ}$ XXXI, 2011 , pp. $261-266$.

6 Véase AGUILAR GARCÍA, María Dolores, «El mercado de Atarazanas», Baética: Estudios de arte, geografía e historia, n. ${ }^{\circ}$ 6, 1983, pp. 7-23; ORDIERES DíEZ, Isabel, Joaquín Rucoba, arquitecto (1844-1919), Santander, Tantín, 1986; RODRíGUEZ MARíN, Francisco José, «La etapa malagueña del arquitecto Joaquín de Rucoba (1844-1919)", Boletín de Arte, n. ${ }^{\circ} 11,1990$, pp. 191-218.

7 PIZARRO GÓMEZ, Francisco Javier, Arquitectura y urbanismo en Trujillo (siglos XVIII y XIX), Cáceres, Universidad de Extremadura, 1987.

8 Archivo Municipal de Cáceres (A.M.C.C.), caja 19/71, expediente 8. La primera proposición de la Empresa General de Construcciones, que ofrece construir el mercado, es de 04-03-1883, luego ratificada en otras cartas posteriores, cuya propuesta oficial es de 17-04-1883.

9 A.M.C.C., libro de actas, sesiones de 19-12-1884 y 26-12-1884. Había depositado 2.600 pesetas en la caja municipal como compromiso de ejecución. El arquitecto municipal opinó que el proyecto era correcto si bien lo consideraba pequeño, pudiendo ampliarse en su longitud, y que debían señalarse los cálculos de resistencia, aunque esto se podía subsanar durante la tramitación del expediente.

10 A.M.C.C., caja 20/40, exp. 6.

11 Véase tesis doctoral de BARROS CANEDA, José Ramón, Arquitectura y Urbanismo en el Puerto de Santa María en el siglo XIX, Sevilla, 1995. En: http:// fondosdigitales.us.es/tesis/tesis/1911/arquitectura-y-urbanismo-en-el-puerto-de-santa-maria-durante-el-siglo-xix/ (Fecha de consulta: 15-01-2015).

12 Aquí realiza el matadero, la plaza de toros y el mercado de la localidad. Véase http://issuu.com/lalineaenblancoynegro.com/docs/la_plaza_de_toros_de_la_I_ nea_de_la_concepci_n y http://listarojapatrimonio.org/lista-roja-patrimonio/wp-content/uploads/Mercado-de-Abastos.pdf (Fecha de consulta: 07-01-2015).

13 CASTAÑER MUÑOZ, La arquitectura del hierro en España...

14 ISAC, Ángel, Eclecticismo y pensamiento arquitectónico en España. Discursos, revistas, congresos, 1846-1919, Granada, Diputación Provincial de Granada, 1987, pp. 306-309.

15 Véase CASTAÑER MUÑOZ, La arquitectura del hierro en España..., p. 88. El autor afirma que a partir de los años 80: «El sistema de cerramiento exterior, típicamente baltardiano en el que los elementos metálicos eran visibles y constituían la base de la composición y de la decoración, fue aquí progresivamente abandonado y reemplazado por cajas de muros construidas con materiales tradicionales".

16 http://listarojapatrimonio.org/lista-roja-patrimonio/wp-content/uploads/Mercado-de-Abastos.pdf (Fecha de consulta: 07-01-2015).

17 A.M.C.C., libros de actas, sesión extraordinaria de 28-07-1885. Las comisiones de ornato y hacienda piden la nulidad del expediente, y opinan «que el proyecto es ruinoso para el Ayuntamiento, que producirán infinitas vejaciones a los vecinos, que ocasionará cada día una cuestión de orden público, y como coronación del edificio, será un semillero de pleitos [...]. Además perdería el Ayuntamiento próximamente tres mil pesetas anuales que hoy cobra», f. 24. En la sesión de 13-08-1885 se lee la instancia presentada por 294 vecinos felicitándole por el acuerdo tomado en la sesión extraordinaria.

18 A.M.C.C., libros de actas, sesión de 03-12-1885.

19 A.M.C.C., libros de actas, sesión de 14-01-1886.

20 A.M.C.C., caja 20/40, exp. 8. Plano plaza de la Carne, año 1886.

21 A.M.C.C., libro de actas, sesiones de 19-06-1886 y 14-08-1886. Se declara que la construcción del mercadillo ha terminado. Se fija el alquiler de los puestos en 50 y 10 céntimos, según sean de primera o segunda clase.

22 A.M.C.C., caja 19/71, exp. 8 y sesión de 22-05-1886. El letrado municipal, dicta su auto el 24-11-1886, siendo crítico aunque benévolo con la actuación llevada a cabo por las comisiones y el ayuntamiento, señalando que en caso de ir a los tribunales el municipio tendría mucho que perder.

23 A.M.C.C., caja 20/47, exps. 5, 8 y 12. Planos solar mercado, año 1910.

24 Véase CÁRCAMO MARTÍNEZ, Joaquín, "Nueva vida para los mercados de hierro en la península ibérica», en Actas de las IX Jornadas Internacionales de Patrimonio Industrial, Del Hierro al Acero. Forjando el Patrimonio Industrial Metalúrgico, 2008, pp. 129-137, en: http://www.academia.edu/attachments/33402000/download_file?st=MTQyMjYONzExMCwxNTAuMjEOLjIwNS4xNTQsNDgzMDQz\&s=work_strip (Fecha de consulta: 21-01-2015).

25 Véase el número monográfico sobre el futuro de los mercados en la revista Distribución y consumo, Mercasa, n. ${ }^{\circ}$ 11, 1993, en http://dialnet.unirioja.es/ ejemplar/217743 (Fecha de consulta: 23-07-2015).

26 Información sobre la historia de los mercados de Barcelona y remodelaciones en http://mercatsbcn.cat; vídeos sobre la reforma del Ninot en el canal oficial del Ayuntamiento de Barcelona en youtube: www.youtube.com/watch?v=8h5PSOfwWu4 y https://www.youtube.com/watch?v=VA5_mpw2xH0 (Fecha de consulta: 22-07-2015).

27 FELIU Assumpció y VILANOVA, Antoni, La Barcelona de ferro. A propòsit de Joan Torras Guardiola, Barcelona, MUHBA, Ajuntament de Barcelona, 2011; ZAVALA SÁNCHEZ, María Dolores, Intervenciones contemporáneas en los mercados municipales representativos de Cataluña y Valencia, construidos a finales del siglo XIX y principios del XX, tesis doctoral dirigida por José Luis González Moreno-Navarro, Universitat Politècnica de Catalunya, Barcelona, 2013, en http://www.tdx.cat/bitstream/handle/10803/134804/TMDZS1de2.pdf?sequence=1 (Fecha de consulta: 18-01-2015)

28 http://www.arangurengallegos.com/ag/portfolio_page/atarazanas-market/ (Fecha de consulta: 29-01-2015).

29 Es el caso de lo que va a ocurrir en Valladolid en 2015; véase el debate y reflexión ciudadanos en https://rarquitectura.wordpress.com/2014/11/18/mercado-del-val-susto-o-muerte/\#comment-183 (Fecha de consulta: 31-01-2015). En este sentido, son muy interesantes también las conclusiones de ZAVALA SÁNCHEZ, Intervenciones contemporáneas en los mercados.. 